\title{
Croatian Registered Nurses - Perception of Barriers to Research Utilization: A Cross-sectional Study
}

\author{
Maja Čebohin ${ }^{1,2} \mathbb{D}$, Dragica Pavlović ${ }^{1,2}$, Robert Smolić ${ }^{1,2}$, Dijana Hnatešen ${ }^{1,2,3}$, Nikolina Farčić ${ }^{1,2,3} \mathbb{D}$, Ksenija Marjanović $^{2,4 *}$ \\ ${ }^{1}$ Department of Nursing and Palliative Medicine, Faculty of Dental Medicine and Health Osijek, Josip Juraj Strossmayer \\ University of Osijek, Nursing Institute "Professor Radivoje Radić", Osijek, Croatia; ${ }^{2}$ Faculty of Medicine, Josip Juraj Strossmayer \\ University of Osijek, Osijek, Croatia; ${ }^{3}$ University Hospital Osijek, Osijek, Croatia; ${ }^{4}$ Clinical Department of Pathology and Forensic \\ Medicine, University Hospital Osijek, Osijek, Croatia
}

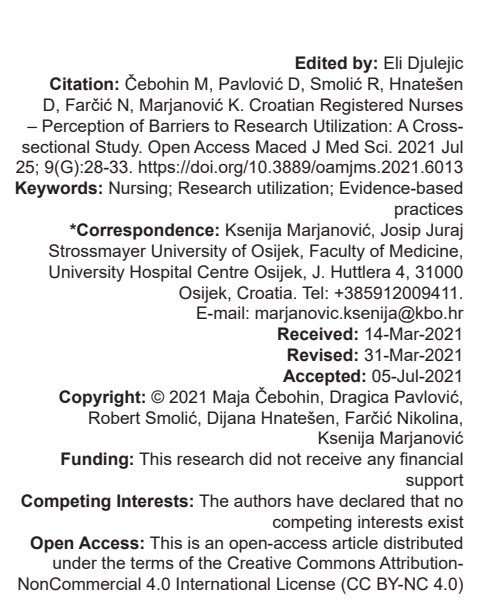

\begin{abstract}
BACKGROUND: Despite positive effects of research utilization on improving the quality of care, nurses meet numerous obstacles when trying to bridge the gap between the theory and utilization of research findings in nursing practice.

AIM: The study was conducted to identify barriers to research utilization in daily nursing practice among registered nurses in University Hospital Center Osijek, Croatia.

PARTICIPANTS AND METHODS: A cross-sectional study was conducted in University Hospital Center Osijek Croatia in 2014. The study included 415 registered nurses, randomly selected. The BARRIERS Scale and a demographic data questionnaire were used to collect data.

RESULTS: The study identified organizational barriers as major obstacles to implementing research findings. The items rated highest were "there is insufficient time on the job to implement new ideas" (78.2\%), "nurse does not fee she/he has enough authority to change patient care procedures" (77.5\%), "relevant literature is not compiled in one place" $(72.1 \%)$, "physicians will not cooperate with implementation" $(70.5 \%)$, and "nurse does not have time to read research" $(70.4 \%)$. The item "relevant literature is not compiled in one place" belongs to communication subscale while the other items belong to organizational barriers subscale.
\end{abstract}

CONCLUSION: Registered nurses employed in University Hospital Center Osijek, Croatia perceived organizational barriers as major obstacles to research utilization.

\section{Introduction}

Research utilization is a term introduced in 1969 [1]. Scientists described it as a process of implementing research findings and research methods to improve daily nursing practice [2], [3]. Estabrook defines research utilization as "the use of research findings in any and all aspects of one's work as a registered nurse" [4]. Research utilization is application of research findings in clinical practice to facilitate decision-making. Melnyk and Fineout-Overholt defined evidence-based practices (EBP) as approach to problem-solving in clinical practice, which includes conscientious application of best evidence available at the moment of making decisions regarding patient care [5]. However, despite positive attitude toward research utilization, as well as toward EBP, many nurses do not use research findings in their clinical practice. Challenges affecting implementation were described by Ketefian in 1975. She concluded: "The practitioner either was totally unaware of the research literature relative to her practice, or, if she was aware of it, was unable to relate to it or utilize it. There was an apparent isolation of research from practice" [6]. Since then, we have witnessed the gap between the research utilization theory and its implementation in clinical practice. EBP is a relatively novel approach to nursing practice in Croatia, since the research itself as well as research utilization is at an early stage of development. Nursing education at university level, both in undergraduate and graduate study programs, was initiated in Osijek in 2010, and within these programs nurses received education in fundamental principles of research. Frasure's systematic review identified and described fourteen instruments used to measure nurses' attitudes toward research utilization. Four of these were designed to measure constructs in Rogers' Model, and one of them was a BARRIERS Scale, which has strongest psychometric properties [7]. This is the reason why it is one of the most commonly used research instruments in measuring nurses' attitudes toward research utilization and therefore it was used in this study as well. This is the first study in Croatia researching the implementation issues of research utilization into daily nursing practice. It can as a guide for planning necessary strategies 
that will improve research utilization following the identification of possible barriers. In the literature, these barriers are classified into subgroups: Organizational, individual, communication, and quality of research [8]. Organizational barriers are related to environment where research findings need to be applied [8], [9]. One of highly ranked organizational barriers described in numerous studies refers to the amount of time required to read, evaluate, analyze, disseminate, and implement research findings into practice [9], [10], [11], [12].

Another organizational barrier frequently described in various studies as major obstacle is lack of authority to change procedures [11], [12]. Furthermore, major organizational obstacle is lack of support from managers for implementation of research findings [12], [13]. Individual barriers described in studies are related to individual characteristics of a nurse, such as values, attitudes, knowledge, and skills [8]. According to the literature, some of perceived major individual barriers are lack of knowledge on research methods, being unaware of existing research findings, and having negative attitude toward research [14]. Communication barriers include the ways of presenting the research. Communication barriers described in some studies are: Statistical analyses are not understandable [10], [15], and literature is not compiled in one place [16]. Therefore, the purpose of this study was to identify barriers to research utilization among registered nurses employed in University Hospital Center Osijek, Croatia, to facilitate implementation of EBP and encourage research culture in nursing.

\section{Materials and Methods}

A cross-sectional study was conducted in University Hospital Center Osijek, Croatia in 2014. A questionnaire on demographic data (age, gender, work experience, and education level) and 29-item BARRIERS Scale [8], were distributed to randomly selected nurses $(n=415)$ to identify perceived barriers to research utilization among Croatian registered nurses working in clinical departments. The participants were invited to complete the questionnaires and return them in sealed envelopes. All participants gave informed consent to voluntarily taking part in the research. Their anonymity was guaranteed.

Research instrument was BARRIERS Scale developed by Funk et al. [8] and first published in 1991. Since then it has been used worldwide to identify the barriers to research utilization in nursing practice. The scale items were derived from the literature on research utilization, the Conduct and Utilization of Research in Nursing project questionnaire [17], and data gathered from nurses. Funk et al. [8] identified four factors, or subscales, and considered that these factors can explain why nurses do not use research findings in their work in clinical settings. Funk et al. also consider the four factors, or subscales, to be in compliance with the factors in Rogers' diffusion of innovation theory [18]. The subscales were labeled in accordance with Rogers' theory:

- $\quad$ The characteristics of the adopter (nurse's research values, skills, and awareness) -8 items

- The characteristics of the organization (organizational barriers) - 8 items

- $\quad$ The characteristics of the innovation (qualities of the research) -6 items

- The characteristics of the communication (research communication) - 6 items.

One item, "the amount of the research information is overwhelming", does not load into any of the four factors. The internal consistency of the four subscales of the BARRIERS scale was established, Cronbach's alpha values for the four subscales were $0.80,0.80,0.72$, and 0.65 , respectively [8]. The participants rated the extent to which they perceive each item as a barrier to research utilization: 1-to no extent, 2-to a little extent, 3-to a moderate extent, 4-to a great extent, and 5-no opinion, but the answers "no opinion" were not scored.

Kolmogorov-Smirnov test was used to examine if the variables were normally distributed. Mean values of continuous variables were expressed as arithmetic mean and standard deviation, and non-normal variables were presented as median and interquartile range. Nominal indicators were presented by frequency distribution for each subscale and percentage. Fisher exact test was used to determine the difference in proportions between two independent samples. Mann-Whitney and Kruskal-Wallis tests were used to determine the differences. The internal consistency reliability of the tool was tested using Cronbach's alpha coefficient [19]. Originally written programs for data bases and statistical package SPSS for Windows (version 26, Carry, NY, USA) at significance level $\alpha=$ 0.05 were used for statistical analysis.

This study was approved by the Ethical Committee of the University Hospital Center Osijek (Approval number: AR1-673-2/2014/2021). Permission to use BARRIERS Scale was obtained from the authors.

\section{Results}

BARRIERS Scale and demographic data questionnaires were distributed to 600 randomly selected registered nurses at various clinical departments, and $415(69.1 \%)$ were returned. The sample included $39(9.4 \%)$ men and 376 (90.6\%) women.

According to the age, most participants, 131 (31.6\%), were $31-40$ years old, followed by 
$106(25.5 \%)$ of $<30$ years of age, where there were significantly more men (Fisher exact test, $p=0.001$ ). There were $97(23.4 \%)$ participants at the age range of $41-50,71(17.1 \%)$ between the ages of 51 and 60 , and $10(2.4 \%)$ participants were 61 and older.

According to work experience, 123 (29.6\%) participants had between 11 and 20 years and $100(24.1 \%)$ between 21 and 30 years of work experience. Men had significantly less work experience (Fisher exact test $p<0.001)$. There were $67(16.1 \%)$ participants who had 31 or more years of experience.

According to level of education, 268 (64.6\%) participants were registered nurses, 126 (30.4\%) had bachelor's degree, and 21 (5.1\%) had master's degree. There was no significant difference regarding gender (Table 1).

Table 1: Socio-demographic characteristics of study sample

\begin{tabular}{|c|c|c|c|c|}
\hline \multirow[t]{2}{*}{ Participants' characteristics } & \multicolumn{3}{|c|}{ Number (\%) of participants } & \multirow[t]{2}{*}{$\mathrm{p}^{*}$} \\
\hline & Men & Women* & Total & \\
\hline \multicolumn{5}{|l|}{ Age } \\
\hline$<30$ & $20(51.3)$ & $86(22.9)$ & $106(25.5)$ & \multirow[t]{5}{*}{0.001} \\
\hline $31-40$ & $14(35.9)$ & $117(31.1)$ & 131 (31.6) & \\
\hline $41-50$ & $4(10.3)$ & $93(24.7)$ & $97(23.4)$ & \\
\hline $51-60$ & $1(2.6)$ & 70 (18.6) & $71(17.1)$ & \\
\hline$>61$ & 0 & $10(2.7)$ & $10(2.4)$ & \\
\hline \multicolumn{5}{|l|}{ Work experience } \\
\hline$<5$ & $8(20.5)$ & $38(10.1)$ & $46(11.1)$ & \multirow[t]{5}{*}{$<0.001$} \\
\hline $6-10$ & $17(43.6)$ & $62(16.5)$ & $79(19)$ & \\
\hline $11-20$ & $9(23.1)$ & $114(30.3)$ & $123(29.6)$ & \\
\hline $21-30$ & $4(10.3)$ & $96(25.5)$ & $100(24.1)$ & \\
\hline$>31$ & $1(2.6)$ & $66(17.6)$ & $67(16.1)$ & \\
\hline \multicolumn{5}{|l|}{ Level of education } \\
\hline Diploma & $30(76.9)$ & $238(63.3)$ & $268(64.6)$ & \multirow[t]{4}{*}{0.057} \\
\hline Bachelor's degree & $6(15.4)$ & $120(31.9)$ & $126(30.4)$ & \\
\hline Master's degree & $3(7.7)$ & $18(4.8)$ & $21(5.1)$ & \\
\hline Total & $39(100)$ & $376(100)$ & $415(100)$ & \\
\hline
\end{tabular}

Table 2 presents rank order of the BARRIERS Scale items along with their mean values and standard deviation. According to more than half of participants,
27 BARRIERS items affect research utilization in practice to a moderate or a great extent. The items "there is insufficient time on the job to implement new ideas" and "the nurse does not feel she/he has enough authority to change patient care procedures" listed in the Organizational Barrier subscale were ranked as number one and number two barriers to research utilization according to $78.2-77.5 \%$ of participants, respectively. These items were followed by the Research Communication subscale item "the relevant literature is not compiled in one place" (72.1\% of participants), while the lowest rated items were "the conclusions drawn from the research are not justified" (Quality of Research subscale) and "the research is not relevant to the nurse's practice" (Research Communication subscale), according to $49.6-42.1 \%$ of participants, respectively (Table 2 ).

Subscale "Organizational Barriers" had the highest score (mean $=2.91, \mathrm{SD}=0.60)$, closely followed by "Nurses' Research Awareness and Values" (mean $=2.66 \mathrm{SD}=0.64$ ), and "Research Communication" (mean $=2.59 \mathrm{SD}=0.64$ ), while the subscale "Quality of Research" (mean $=2.57, \mathrm{SD}=0.60$ ) had the lowest score. The mean overall score (out of 4 ) for the Barriers Scale was $2.66(\mathrm{SD}=0.55)$ (Table 3$)$.

The results showed higher scores in men than in women, in nurses who had master's degree in comparison to other levels of education, as well as in participants between the ages of 31 and 40 and those with work experience in the range of 11-20 years. However, there was no statistically significant difference according to gender, age, level of education, and work experience (Table 4).

Table 2: Percentage of nurses who rate each barrier as great or moderate and the rank order of barriers $(\mathrm{n}=415)$

\begin{tabular}{|c|c|c|c|c|c|}
\hline Rank order & Questionnaire Items & Subscale & $\begin{array}{l}\text { Rati } \\
\text { or gr }\end{array}$ & $\begin{array}{l}\text { s moderate } \\
\text { er } n(\%)\end{array}$ & $\begin{array}{l}\text { Barrier Item } \\
\text { Mean (SD) }\end{array}$ \\
\hline 1 & There is insufficient time on the job to implement new ideas & Organizational Barriers & 294 & 78.2 & $3.2(0.97)$ \\
\hline 2 & $\begin{array}{l}\text { The nurse does not feel she/he has enough authority to change patient care } \\
\text { procedures }\end{array}$ & Organizational Barriers & 300 & 77.5 & $3.11(0.95)$ \\
\hline 3 & The relevant literature is not compiled in one place & Research Communication & 277 & 72.1 & $2.99(1.0)$ \\
\hline 4 & Physicians will not cooperate with implementation & Organizational Barriers & 249 & 70.5 & $2.93(0.97)$ \\
\hline 5 & The nurse does not have time to read research & Organizational Barriers & 280 & 70.4 & $2.92(1.02)$ \\
\hline 6 & The nurse sees little benefit for self & Nurses' Research Awareness and Values & 268 & 69.6 & $2.86(0.94)$ \\
\hline 7 & The nurse feels results are not generalizable to own setting & Organizational Barriers & 257 & 69.3 & $2.84(0.8)$ \\
\hline 8 & The nurse feel the benefits of changing practice will be minimal & Nurses' Research Awareness and Values & 256 & 68.4 & $2.83(0.93)$ \\
\hline 9 & Other staff are not supportive of implementation & Organizational Barriers & 253 & 67.8 & $2.88(0.93)$ \\
\hline 10 & Implications for practice are not made clear & Research Communication & 272 & 67.5 & $2.79(0.89)$ \\
\hline $10^{*}$ & There is not a documented need to change practice & Nurses' Research Awareness and Values & 257 & 67.5 & $2.86(0.93)$ \\
\hline 12 & Administration will not allow implementation & Organizational Barriers & 216 & 64.7 & $2.83(1.03)$ \\
\hline 13 & The research has not been replicated. & Quality of Research & 210 & 63.6 & $2.72(0.98)$ \\
\hline $13^{*}$ & The nurse does not see the value of research for practice & Nurses' Research Awareness and Values & 245 & 63.6 & $2.7(1.01)$ \\
\hline 15 & Research reports/articles are not published fast enough & Quality of Research & 226 & 61.6 & $2.69(0.92)$ \\
\hline 16 & The facilities are inadequate for implementation & Organizational Barriers & 234 & 61.4 & $2.71(1.1)$ \\
\hline 17 & Statistical analyses are not understandable & Research Communication & 233 & 60.8 & $2.68(0.98)$ \\
\hline 18 & $\begin{array}{l}\text { The nurse is isolated from knowledgeable colleagues within whom to discuss the } \\
\text { research }\end{array}$ & Nurses' Research Awareness and Values & 221 & 59.4 & $2.67(0.99)$ \\
\hline $18^{*}$ & The literature reports conflicting results & Quality of Research & 205 & 59.4 & $2.6(0.9)$ \\
\hline 20 & The amount of research information is overwhelming & ${ }^{*}$ Redundant in Funk's Scale & 214 & 59 & $2.64(0.94)$ \\
\hline 21 & The nurse is uncertain whether to believe the results of the research & Quality of Research & 217 & 58.6 & $2.6(0.99)$ \\
\hline 22 & The research is not reported clearly and readably & Research Communication & 207 & 58.3 & $2.59(1.01)$ \\
\hline 23 & Research reports/articles are not readily available. & Research Communication & 221 & 57.4 & $2.51(0.97)$ \\
\hline 24 & The nurse is unwilling to change/try new ideas & Nurses' Research Awareness and Values & 219 & 56.6 & $2.57(1.03)$ \\
\hline $24^{*}$ & The nurse does not feel capable of evaluating the quality of research & Nurses' Research Awareness and Values & 201 & 56.6 & $2.57(0.97)$ \\
\hline 26 & The research has methodological inadequacies & Quality of Research & 191 & 55.2 & $2.5(0.95)$ \\
\hline 27 & The nurse is unaware of the research & Nurses' Research Awareness and Values & 199 & 53.5 & $2.52(1.09)$ \\
\hline 28 & The conclusions drawn from the research are not justified & Quality of Research & 177 & 49.6 & $2.41(0.88)$ \\
\hline 29 & The research is not relevant to the nurse's practice & Research Communication & 157 & 42.1 & $2.19(1.13)$ \\
\hline
\end{tabular}


Table 3: Mean values, standard deviation, and Cronbach's alpha of the Barriers Scale total and subscale scores $(n=415)$

\begin{tabular}{lll}
\hline Subscale & Mean (SD) & Cronbach's Alpha \\
\hline Nurses' Research Awareness and Values & $2.66(0.64)$ & 0.810 \\
Organizational Barriers & $2.91(0.60)$ & 0.790 \\
Quality of Research & $2.57(0.60)$ & 0.746 \\
Research Communication & $2.59(0.64)$ & 0.726 \\
\hline Barrier Scale total & $2.66(0.55)$ & 0.933
\end{tabular}

\section{Discussion}

Application of best research findings in daily nursing practice to improve the patient care is a challenge for every nurse and simultaneously a goal nurses aspire to. Research findings, although available, are not immediately applied in practice, due to numerous barriers perceived by healthcare professionals, which is described in the literature. Therefore, the purpose of this study was to identify barriers to research utilization in registered nurses employed in University Hospital Center Osijek, Croatia. This study included significantly larger number of female participants $(90.6 \%)$, which complies with many other studies [11], [13], [16], [20], [21], [22], [23], with exception of the study carried out in Saudi Arabia where all participants were men [24]. According to more than half of participants in this study, 27 BARRIERS items affect research utilization in practice to a moderate or a great extent. In addition, the mean total score for items in the BARRIERS Scale was as high as 2.66 out of 4 ,

Table 4: Perception of barriers according to participants' characteristics

\begin{tabular}{|c|c|c|c|}
\hline \multirow[t]{2}{*}{ Participants' characteristics } & \multicolumn{2}{|l|}{ Total } & \multirow[t]{2}{*}{$\mathrm{p}^{*}$} \\
\hline & Median (interquartile range) & Minimum-Maximum & \\
\hline \multicolumn{4}{|l|}{ Gender } \\
\hline Men & $3.05(2.62-3.22)$ & $1.90-3.38$ & \multirow[t]{2}{*}{0.140} \\
\hline Women & $2.76(2.28-3.07)$ & $1.00-3.90$ & \\
\hline \multicolumn{4}{|l|}{ Age } \\
\hline$<30$ & $2.60(2.14-3.00)$ & $1.00-3.38$ & \multirow[t]{5}{*}{0.299} \\
\hline $31-40$ & $2.90(2.52-3.10)$ & $1.79-3.90$ & \\
\hline $41-50$ & $2.67(2.21-3.07)$ & $1.34-3.48$ & \\
\hline $51-60$ & $2.62(2.21-3.00)$ & $1.34-3.52$ & \\
\hline$>61$ & $2.76(2.00-3.17)$ & $1.62-3.31$ & \\
\hline \multicolumn{4}{|l|}{ Work experience } \\
\hline$<5$ & $2.79(2.34-3.03)$ & $1.62-3.34$ & \multirow[t]{5}{*}{0.225} \\
\hline $6-10$ & $2.72(2.10-3.07)$ & $1.00-3.62$ & \\
\hline $11-20$ & $2.86(2.52-3.10)$ & $1.79-3.90$ & \\
\hline $21-30$ & $2.62(2.14-3.00)$ & $1.34-3.48$ & \\
\hline$>31$ & $2.76(2.34-3.07)$ & $1.34-3.52$ & \\
\hline \multicolumn{4}{|l|}{ Level of education } \\
\hline Diploma & $2.76(2.21-3.07)$ & $1.00-3.90$ & \multirow[t]{3}{*}{0.714} \\
\hline Bachelor's degree & $2.76(2.28-3.03)$ & $1.34-3.48$ & \\
\hline Master's degree & $2.95(2.43-3.12)$ & $1.76-3.52$ & \\
\hline
\end{tabular}

and the mean for 26 items was higher than 2.5. Mean value $>2.5$ in BARRIERS Scale is generally considered high, according to the various studies [8], [25]. It can be explained by the fact that research utilization and nursing research in Croatia are at an early stage of development. The internal consistency reliability calculated for each subscale in this study is in agreement with other studies using BARRIERS Scale, ranging from 0.67 to 0.88 , which indicates good reliability [8], [26], [27]. According to participants in this study, organizational barriers are major barriers to research utilization. The organizational barriers subscale item "there is insufficient time on the job to implement new ideas" was ranked the greatest barrier to research utilization in Clinical Hospital Center Osijek by $78.2 \%$ of participants. This finding is supported by the studies carried out in China [1], Nepal [28], and Maldives [29]. The item ranked as second highest was also from the organizational barriers subscale, "the nurse does not feel she/he has enough authority to change patient care procedures", which complies with other studies [11], [16], [21], [29], [30], [31]. It is followed by the item from the research communication subscale "the relevant literature is not compiled in one place" according to $72.1 \%$ of participants, which is corroborated by the results of a study carried out in Sweden [14]. "Physicians will not cooperate with implementation" was the item ranked number four, which is in agreement with other studies [20], [32], while number five was the item "the nurse does not have time to read research" according to $70.4 \%$ of RNs in University Hospital Center Osijek These results are in compliance with the other studies [14], [29]. The results showed that four of the first five items belonged to organizational subscale, and similar results were obtained in other studies [11], [21]. Therefore, to ensure EBP and research utilization in University Hospital Center Osijek, the local organizational barriers need to be addressed. Regarding the level of education, participants with master's degree perceive greater barriers to research utilization in comparison to other participants. Similar results were presented in the study carried out in Hong Kong [11]. Numerous studies state that advanced education is an important facilitator of research utilization [11], [32]. Thus, strategic approach to this problem is required, which includes educational workshops, effective research leadership, and mentorship, providing motivation, and replacing culturally traditional attitudes with research findings to enable application of best practice. The study carried out in Ghana described system of rewards given by institution's management to nurses who implement research findings in their daily practice as one of the strategies to encourage positive research culture [22].

This study has certain limitations, since it included only a group of registered nurses in one University hospital, which means that the obtained results cannot be considered valid for Croatian nurses in general. Taking into account the fact that this was the first study aimed to research the perception of barriers to research utilization in nursing practice, it is necessary to conduct further research and include greater number of nurses in Croatia.

\section{Conclusion}

The results of this study indicated that organizational barriers were the most significant barriers to research utilization in registered nurses 
employed in University Hospital Center Osijek, Croatia. Better organizational support and advanced education to increase research knowledge should be addressed to provide EBP in nursing, which will result in better patient outcomes. This is initial step in fostering EBP in nursing. Since changes always happen gradually, research utilization is a slow process that requires hard work.

\section{References}

1. Zhou F, Maier M, Hao Y, Tang L, Guo H, Liu H, et al. Barriers to research utilization among registered nurses in traditional Chinese medicine hospitals: A cross-sectional survey in China. Evid Based Complement Alternat Med. 2015;2015:475340. https://doi.org/10.1155/2015/475340 PMid:26649060

2. Stetler CB. Research utilization: Defining the concept. Image $J$ Nurs Sch. 1985;17(2):40-4.

PMid:3846562

3. Estabrooks CA. The conceptual structure of research utilization. Res Nurs Health. 1999;22(3):203-16. PMid: 10344701

4. Estabrooks CA. Will evidence-based nursing practice make practice perfect? Can J Nurs Res. 1998;30(1):15-36. PMid: 10603800

5. Melnyk BM, Fineout-Overholt E. Evidence-Based Practice in Nursing and Healthcare. Philadelphia, PA: Wolters Kluwer; 2005. p. 6-10.

6. Ketefian S. Application of selected nursing research findings into nursing practice: A pilot study. Nurs Res. 1975;24(2):89-92. https://doi.org/10.1097/00006199-197503000-00003 PMid:1038621

7. Frasure J. Analysis of instruments measuring nurses' attitudes towards research utilization: A systematic review. J Adv Nurs. 2008;61(1):5-18.

PMid:18173733

8. Funk SG, Champagne MT, Wiese RA, Tornquist EM. Barriers: The barriers to research utilization scale. Appl Nurs Res. 1991;4(1):39-45. https://doi.org/10.1037/t61247-000

\section{PMid:1741634}

9. Funk SG, Tornquist EM, Champagne MT. Barriers and facilitators of research utilization. An integrative review. Nurs Clin North Am. 1995;30(3):395-407. PMid:7567566

10. ParahooK.Barriersto, andfacilitatorsof, researchutilizationamong nurses in Northern Ireland. J Adv Nurs. 2000;31(1):89-98. https:// doi.org/10.1046/j.1365-2648.2000.01256.x

PMid:10632797

11. Thompson DR, Chau JP, Lopez V. Barriers to, and facilitators of, research utilisation: A survey of Hong Kong registered nurses. Int J Evid Based Healthc. 2006;4(2):77-82. https://doi. org/10.1111/j.1479-6988.2006.00036.x

PMid:21631759

12. Hutchinson AM, Johnston L. Bridging the divide: A survey of nurses' opinions regarding barriers to, and facilitators of, research utilization in the practice setting. J Clin Nurs. 2004;13(3):304-15. https://doi.org/10.1046/j.1365-2702.2003.00865.x

PMid:15009333
13. Bryar RM, Closs SJ, Baum G, Cooke J, Griffiths J, Hostick T, et al. The Yorkshire BARRIERS project: Diagnostic analysis of barriers to research utilisation. Int J Nurs Stud. 2003;40(1):73-84. https://doi.org/10.1016/s0020-7489(02)00039-1 PMid:12550152

14. Boström AM, Kajermo KN, Nordström G, Wallin L. Barriers to research utilization and research use among registered nurses working in the care of older people: Does the BARRIERS Scale discriminate between research users and non-research users on perceptions of barriers? Implement Sci. 2008;3(1):24. https:// doi.org/10.1186/1748-5908-3-24 PMid: 18452603

15. Marsh GW, Nolan M, Hopkins S. Testing the revised barriers to research utilization scale for use in the UK. Clin Eff Nurs. 2001;5(2):66-72. https://doi.org/10.1054/cein.2001.0192

16. Patiraki E, Karlou C, Papadopoulou D, Spyridou A Kouloukoura C, Bare E, et al. Barriers in implementing research findings in cancer care: The Greek registered nurses perceptions. Eur J Oncol Nurs. 2004;8(3):245-56. https://doi. org/10.1016/j.ejon.2003.12.002

PMid:15304232

17. Horsley JA, Crane J, Bingle J. Research utilization as an organizational process. J Nurs Adm. 1978;8(7):4-6.

18. Rogers EM. Diffusion of Innovations. $5^{\text {th }}$ ed. India: Free Press; 2003.

19. Munro BH, Page EB. Statistical Methods for Health Care Research. $2^{\text {nd }}$ ed. Philadelphia, PA: JB Lippincott; 1993.

20. Aljezawi M, Al Qadire M, Alhajjy MH, Tawalbeh LI, Alamery AH, Aloush $\mathrm{S}$, et al. Barriers to integrating research into clinical nursing practice. J Nurs Care Qual. 2019;34(3):E7-11. https:// doi.org/10.1097/ncq.0000000000000371 PMid:30480612

21. Chau JP, Lopez V, Thompson DR. A survey of Hong Kong nurses' perceptions of barriers to and facilitators of research utilization. Res Nurs Health. 2008;31(6):640-9. https://doi. org/10.1002/nur.20289

PMid:18523978

22. Nkrumah I, Atuhaire C, Priebe G, Cumber SN. Barriers for nurses' participation in and utilisation of clinical research in three hospitals within the Kumasi Metropolis, Ghana. Pan Afr Med J. 2018;30:24.https://doi.org/10.11604/pamj.2018.30.24.15230 PMid:30214657

23. Umarani J. A study to assess the perceived barriers to evidence based practice among registered nurses. Asian J Biomed Pharm Sci. 2014;4(32):15-9.

24. Samarkandi OA, Bashatah AS, Khan AA, Almobrad AM, Beovich B, Williams B. Research utilization barriers for emergency medical technicians in Saudi Arabia. Adv Med Educ Pract. 2018;9:519-26. https://doi.org/10.2147/amep.s150604 PMid:30046264

25. Brown CE, Ecoff L, Kim SC, Wickline MA, Rose B, Klimpel K, et al. Multi-institutional study of barriers to research utilisation and evidence-based practice among hospital nurses. J Clin Nurs. 2010;19(13-14):1944-51. https://doi. org/10.1111/j.1365-2702.2009.03184.x PMid:20920021

26. Chen SH, Shao JH, Hsiao YC, Lee HC. Barriers to research utilization by registered nurses in Taiwan. Res Nurs Health. 2013;36(2):191-202. https://doi.org/10.1002/nur.21521 PMid:23408357

27. Temel AB, Uysal A, Ardahan M, Ozkahraman S. Barriers to research utilization Scale: Psychometric properties of the Turkish version. J Adv Nurs. 2010;66(2):456-64. https://doi. org/10.1111/j.1365-2648.2009.05162.x

PMid:19796118 
28. Kc S, Subramaniam PR, Paudel S. Barriers and facilitators of utilizing research among nurses in Nepal. J Contin Educ Nurs. 2016;47(4):171-9. https://doi. org/10.3928/00220124-20160322-07

PMid:27031032

29. Shifaza F, Evans D, Bradley H. Nurses' perceptions of barriers and facilitators to implement EBP in the maldives. Adv Nurs. 2014;2014:698604. https://doi.org/10.1155/2014/698604

30. Al Khalaileh M, Al Qadire M, Musa AS, Al-Khawaldeh OA, Al Qudah $\mathrm{H}$, Alhabahbeh A. Closing the gap between research evidence and clinical practice: Jordanian nurses' perceived barriers to research utilisation. J Educ Pract. 2016;7(8):52-7. https://doi.org/10.1016/j.pmn.2012.08.006
31. Wang LP, Jiang XL, Wang L, Wang GR, Bai YJ. Barriers to and facilitators of research utilization: A survey of registered nurses in China. PLoS One. 2013;8(11):e81908. https://doi. org/10.1371/journal.pone.0081908

PMid:24312380

32. Moreno-Casbas T, Fuentelsaz-Gallego C, de Miguel AG, González-María E, Clarke SP. Spanish nurses' attitudes towards research and perceived barriers and facilitators of research utilisation: A comparative survey of nurses with and without experience as principal investigators. J Clin Nurs. 2011;20(13-14):1936-47. https://doi. org/10.1111/j.1365-2702.2010.03656.x

PMid:21539627 